\title{
Burnout Behaviour and its Psychological Influence on Productivity of Secondary School Teachers in Bungoma South Sub-County, Kenya
}

\author{
Catherine Meddiatrix Wanyonyi*, Dr. Moses Poipoi \\ Masinde Muliro University of Science and Technology, Kenya \\ *Corresponding Author: Catherine Meddiatrix Wanyonyi, Masinde Muliro University of Science and \\ Technology, Kenya
}

\begin{abstract}
Burnout is persistent physical, mental or emotional exhaustion caused by long term stress, resulting from excessive workplace and/or personal responsibilities. The purpose of this study was to determine burnout behaviour and its influence on productivity of teachers in public secondary schools in Bungoma South Sub-County. The focus of the study was on the, psychological influence of burnout behaviour on productivity of teachers. Survey research design was adopted which generated qualitative and quantitative data. Stratified random sampling technique was used to select 12 secondary schools and 121 teachers. One Sub-County Director of Education and 12 principals from the selected secondary schools were purposively sampled. Primary data was collected from the respondents using a questionnaire and interview schedules while secondary data was collected using document analysis guide. Descriptive statistics such as frequency counts, percentages and means and inferential statistics (ANOVA) was used to analyse data. Qualitative data was received in verbatim, cleaned and presented in themes and sub themes. Results indicate a positive psychological influence of burnout behavior on productivity of teachers. The study concluded that the psychological influence of burnout behaviour moderately influences the productivity of teachers and therefore recommended that the Ministry of Education Science and Technology and the Teachers Service Commission should develop policies that will; minimize if note eliminate situations of teacher stagnation in the same grade for many year; obligate parents to play their role by paying the mandatory school fees on time so that students are not send away to collect fees and the school management to engage parents to appreciate the capabilities of their children so that they do not put unrealistic demands on the teachers. It is hoped that findings of this study may equip education stakeholders with information to understand better the psychological influence of burnout behavior on productivity of teachers, its prevention and management.
\end{abstract}

Keywords: Burnout Behaviour, Influence, Psychological, Productivity, Teacher

Abbreviations: KCSE-Kenya Certificate of Secondary Education; MOEST -Ministry of Education Science and Technology; SDOE-Sub-County Director of Education; TSC-Teachers Service Commission

\section{INTRODUCTION}

Burnout is a phenomenon that has been widely studied. Teacher burnout is a destructive force in today's educational establishment, and its effects should not be trivialized. Characterized by emotional exhaustion, depersonalization, and decreased teacher efficacy; burnout threatens educational quality by leading to early attrition and loss of productivity. Common characteristics have been observed, yet little has been done explicitly to impact the issue. Burnout is not only a mental state but a true psychological condition that negatively affects every aspect of a teacher's life. Policy members and community members are completely unaware of the physiological and psychological ramifications of teaching. Teachers are burnt-out and are consequently facing dangerous consequences. Some of the common autoimmune disorders that are triggered by burnout are diabetes, lupus, sjorgren's and celiac disease.

As a whole studies show that burnout has been associated with high absenteeism, ineffectiveness, interpersonal conflicts, lower level of productivity, lack of commitment, dissatisfaction with job, self-esteem, turnover and an inability to take work seriously. Therefore burnout can result in reduced job satisfaction, reduced productivity, increased absenteeism, increased turnover, and can negatively impact employee's physical health. 
In a report on School Based Programmes (2008) burnout was described as a debilitating psychological condition brought about by unrelieved work stress, resulting in depleted energy and emotional exhaustion, lowered resistance to illness, increased depersonalization in interpersonal relationships, increased dissatisfaction and pessimism and increased absenteeism and work inefficiency. In addition, student discipline is considered the critical aspect for teachers' exhaustion and the primary stress factor for teachers.

Teachers are more burned out when faced with greater numbers of students with behavior problems and learning disabilities. Student behavior is an increasing factor of stress, especially among secondary level teachers. A study found 10 specific student behaviors to be statistically significant contributors to teacher stress. They include: hostility towards the teacher, not paying attention during class, noisiness, lack of effort in class, coming to class unprepared, hyperactivity, breaking school rules, harming school property, hostility toward other students, and lack of interest in learning. Other burnout symptoms may include high absenteeism, lack of commitment, abnormal desire for vacations, low satisfaction, self-esteem, and an inability to take work seriously.

Another study explored burnout level of secondary school teachers with reference to demographic variables like age, gender, marital status and place of living in Aligarh district of Uttar Pradesh revealed that secondary school teachers have lower level of burnout in all three dimensions of burnout (emotional exhaustion, depersonalisation, and personal accomplishment). The study also found that secondary school teachers do not differ significantly on their level of burnout according to age, gender and marital status but they significantly differ according to their place of living.

An Integrative Approach to Burnout in Secondary School Teachers examined the main occupational stressors within the teaching profession found that students, teachers, parents, lawmakers seem to be rivaling for a place in the explanation of professional distress. A sample of some arguments in this domain include decreased student motivation, increased classroom conflict, student cultural diversity, changes in teacher-student interaction, displacement of educational responsibility from the parents towards the educational system, legal reforms and raising the age of compulsory schooling.

Further, a teacher has been used as the scapegoat responsible at least in part for the ills of the educational system. Demands like being a good teacher, educator and efficient psychologist able to integrate diversity and with ability to handle difficult situations efficiently has led to some of them to manifest marked feelings of emotional exhaustion, depersonalisation and a decreased feeling of competence. Student disruptive behaviour and attitudes (aggressions among students and against their teachers, vandalism, challenging the competence and professionalism of teachers) are occupational distress triggering factors. The difficulty in dealing with potentially conflictive situations (meeting the parents of conflictive students, maintaining discipline within the classroom, solving problems and student disruptive behaviour) and a perception of lack of support and consensus in disciplinary matters (parents, co-workers, supervisors) has also become one solid predictive argument in secondary school teacher burnout.

In Nigeria, the relationship between Academic burnout, Self-efficacy and Academic engagement among Nigerian college students was explored. Results showed that burnout was negatively related with academic engagement. The main sources of teacher stress stem from difficulty in maintaining classroom discipline, time pressures, workload demands, excessive change, being evaluated by others, challenging relationships with colleagues and poor working conditions. It was asserted that there is a significant relationship between occupational stressors and the stress experienced by teachers at high risk secondary schools in the Western Cape and that occupational stress is related to job satisfaction, job overload and job control

\subsection{Theoretical Framework}

The researcher used the Grand theory of burnout and the Persistent burnout theory to demonstrate that non-fulfillment of workers expectation and lack of adequate recreation facilities, poor infrastructure and excessive workload leads to burnout behavior that affects productivity. The Grand theory demonstrates teacher needs at the work place but does not adequately demonstrate how fatigue 
manifests and its influence on productivity hence the gap was addressed by the Persistent Burnout theory that explicitly demonstrates fatigue and its consequences.

\section{ReSEARCH Methodology}

The study adopted a descriptive survey research design that combined both quantitative and qualitative research strategies. A descriptive survey is most appropriate for studying users' attitudes, values and beliefs (Sekaran, 2008; Orodho, 2005). The research population of the study was drawn from public secondary schools in Bungoma South Sub-County that have posted Kenya Certificate of Secondary School Education (KCSE) results from the year 2012 to 2016. The population of interest for this study comprised 1 Sub-County Director of Education, 41 principals and 606 teachers in public secondary schools in Bungoma South Sub-County. Both purposive and stratified random sampling techniques were used to select the study participants. Purposive sampling technique was used because according to Kumar (1999) respondents are best suited to give information concerning the teachers' performance. Kombo (2006) asserts that purposive sampling ensures that those selected as participants are rich in the required information and knowledge of the study. Stratified random sampling technique is a process of selecting a sample by dividing a population into sub groups called strata (Mugenda and Mugenda 2003) and ensures proportionate representation of the population in the sample (Oso, 2005). One (1) Sub-County Director of Education and twelve (12) principals were purposively sampled because they were considered key informants in this study. Stratified random sampling technique was used to sample one hundred and twenty one (121) teachers from twelve public secondary schools that had posted Kenya Certificate of Secondary Education results from 2012 to 2016. A total of one hundred and thirty four (134) respondents participated in the study. According to Kerlinger (2004) an ideal sample should consist of $10 \%$ to $30 \%$ of the target population. The study used three research instruments to collect data: document analysis guide, interview schedule for the SDOE and Principals and a questionnaire for teachers.

Before collecting the actual data, a pilot study was conducted in three secondary schools in Bungoma South Sub-County. Though there are different forms of research validity as specified by Cohen et al. (2007) the researcher used content validity to ascertain the instruments' validity since they (instruments) were developed by the researcher. To ensure validity, the instruments contained possible items that brought out facts about burnout behaviour and its influence on productivity of teachers. Test retest of the research instrument was used to realise a coefficient correlation of 0.81 . The study employed both qualitative and quantitative research method to collect data. The data collected from the field was sorted, edited to correct any mistakes noted, classified and tabulated. The analysis of the collected data was done along the research objectives. This made it easy for the researcher to transcribe the data into themes, sub-themes and categories. Qualitative data was transcribed in themes, sub-themes and categories then reported in an on-going process. Quantitative data on the other hand was collected and analysed using simple descriptive statistics such as frequency counts, means, and percentages. Inferential statistics such as ANOVA at alpha $=0.05$ and $95 \%$ confident interval were also used in data analysis to test the degree of variation on the statements that were posed to respondents.

\section{RESULTS AND DISCUSSION}

The study sought to find out the psychological influence of burnout behavior on productivity of secondary school teachers. The quantitative data were analyzed with the help of a computer software namely Statistical Package for Social Sciences (SPSS) windows version 17.0.

The subsequent sections present the findings of the study according to the research question: What is the psychological influence of burnout behaviour on productivity of secondary school teachers in Bungoma South Sub-County? To help the researcher to draw valid conclusions in line with the research questions, analysis of variance (ANOVA) was performed at alpha $=0.05$ level and 95\% confident interval on the statements that were used to collect both qualitative and quantitative data.

The researcher sought to determine the psychological influence of burnout behaviour on productivity using the research question. What is the psychological influence of burnout behaviour on productivity of secondary school teachers in Bungoma South Sub-County? Respondents were asked to indicate their level of agreement to six statements that were provided as shown in Table 1. 
Burnout Behaviour and its Psychological Influence on Productivity of Secondary School Teachers in Bungoma South Sub-County, Kenya

Table1. Distribution of Respondents on the Psychological Influence of Burnout Behaviour on Productivity of Teachers

\begin{tabular}{|l|l|l|l|l|l|l|l|}
\hline \multicolumn{1}{|c|}{ Statement } & \multicolumn{1}{|c|}{ SA } & \multicolumn{1}{|c|}{ A } & \multicolumn{1}{|c|}{ U } & \multicolumn{1}{c|}{ D } & \multicolumn{1}{c|}{ SD } & \multicolumn{1}{c|}{ Total } \\
\hline I feel emotionally drained from my work. & (f) & 10 & 22 & 4 & 36 & 24 & 96 \\
\hline & $(\%)$ & 10.4 & 22.9 & 4.2 & 37.5 & $25.0 \%$ & 100 \\
\hline $\begin{array}{l}\text { I feel tired when I get up in the morning } \\
\text { and have to face another day work }\end{array}$ & (f) & 7 & 13 & 6 & 37 & 33 & 96 \\
\hline & $(\%)$ & 7.3 & 13.5 & 6.3 & 38.5 & 34.4 & 100 \\
\hline I feel frustrated by my job. & (f) & 8 & 8 & 8 & 30 & 42 & 96 \\
\hline & $(\%)$ & 8.3 & 8.3 & 8.3 & $31.3 \%$ & 43.8 & 100 \\
\hline $\begin{array}{l}\text { As a teacher I deal with emotional } \\
\text { problems very calmly. }\end{array}$ & (f) & 32 & 47 & 6 & 3 & 8 & 96 \\
\hline & $(\%)$ & 33.3 & 49.0 & 6.3 & 3.1 & 8.3 & 100 \\
\hline $\begin{array}{l}\text { I deal effectively with the problems of } \\
\text { students and/or colleagues }\end{array}$ & (f) & 35 & 51 & 5 & 4 & 1 & 96 \\
\hline & (\%) & 36.5 & 53.1 & 5.2 & 4.2 & 1.0 & 100 \\
\hline Sometimes my behavior scares students & (f) & 3 & 10 & 2 & 37 & 44 & 96 \\
\hline & (\%) & 3.1 & 10.4 & 2.1 & 38.5 & 45.8 & 100 \\
\hline
\end{tabular}

Key: SA- Strongly Agree; A- Agree; U- Undecided; D-Disagree; SD- Strongly Disagree

From Table 1, 10.4\% of the respondents strongly agree that they feel emotionally drained from their work, this was asserted by $22.9 \% .4 .2 \%$ were undecided. However a majority $37.5 \%$ disagreed and $25.0 \%$ strongly disagreed. As regards to respondents feeling tired when they get up in the morning to face another day at work, $7.3 \%$ strongly agreed, $13.5 \%$ agree, $6.3 \%$ were undecided, $38.5 \%$ disagreed and $34.4 \%$ strongly disagreed. Further still $8.3 \%$ respondents strongly agreed that they feel frustrated by their job, $8.3 \%$ agreed, $8.3 \%$ were undecided, $31.3 \%$ disagreed and $43.8 \%$ strongly disagreed.

From the study results majority $(82.3 \%)$ of the respondents indicated that they deal with emotional problems very calmly. This is represented by $33.3 \%$ who strongly agreed and $49.0 \%$ agreed. Dealing with emotional problems calmly contributes positively to teachers' productivity. On the contrary, $6.3 \%$ were undecided, $3.5 \%$ disagreed while $8.3 \%$ strongly disagreed. Under normal circumstances, good results are posted when students and colleagues problems are dealt with effectively. 33.3\% respondents strongly agreed that they deal effectively with problems of students and/or colleagues. This was affirmed by $53.1 \%$. However $5.2 \%$ were undecided, $4.2 \%$ disagreed and $1.0 \%$ strongly disagreed. When students' problems are not dealt with effectively by the teachers, their performance is likely to be affected. This in effect impacts negatively on the teachers' productivity since the measure is the students' academic performance at the end of form four.

Respondents were further asked to comment on whether scary teachers' behavior is likely to affect learning. $10.4 \%$ agreed, $3.1 \%$ strongly agreed, $2.1 \%$ were undecided, $38.5 \%$ disagreed and $45.8 \%$ strongly disagreed that sometimes their behavior scares student. The results support those of Taheri et.al(2012) in a study conducted in Isfahan that revealed frustration as one of the ways in which burnout manifests itself and the statement by Smith, Sarason and Sarason, (1982) that; frustration causes emotional exhaustion in excellent performers who eventually lose enthusiasm and concern for their jobs. Further, these results were consistent with results reported by Ndugu (2014) who concluded that attitude is a teacher quality factor that significantly affects teacher productivity.

\subsection{Analysis of Variance on the Psychological Influence of Burnout Behavior on Productivity of Teachers}

An analysis of variance (ANOVA) at alpha $=0.05$ level and $95 \%$ confident interval was performed to test the degree of variation on various statement that were used by the researcher to determine the psychological influence of burnout behaviour on productivity of teachers. The statements include; I feel emotionally drained from my work, I feel tired when I get up in the morning and have to face another day at work, I feel frustrated by my job, as a teacher I deal with emotional problems very calmly, I deal effectively with the problems of students and/or colleagues and sometimes my behavior scares students and the results are as indicated in Table 2 
Burnout Behaviour and its Psychological Influence on Productivity of Secondary School Teachers in Bungoma South Sub-County, Kenya

Table2. Analysis of Variance on Psychological Influence of Burnout Behaviour on Productivity of Teachers

\begin{tabular}{|l|l|l|l|l|l|l|}
\hline \multicolumn{1}{|c|}{ ANOVA } & \multicolumn{1}{c|}{} & & & & & \\
\hline Source of Variation & \multicolumn{1}{c|}{ SS } & df & \multicolumn{1}{c|}{ MS } & F & P-value & F critical \\
\hline Rows & 231.5 & 4 & 57.875 & 0.158616 & 0.955266 & 3.259167 \\
\hline Columns & 1413.75 & 3 & 471.25 & 4.291538 & 0.032209 & 3.490295 \\
\hline Error & 4378.5 & 12 & 364.875 & & & \\
\hline Total & 6023.75 & 19 & & & & \\
\hline
\end{tabular}

Study findings in Table 2 revealed that there is no significant degree of variation in the statements that were used since the P-value of 0.032209 in the columns is less than alpha 0.05 level under the confidence interval of $95 \%$. Therefore, there is a positive psychological influence of burnout behavior on productivity of teachers.

\subsection{Influence of Teachers' Work on other People's Lives}

The study further sought to establish whether the work of secondary school teachers has an influence on other peoples' lives and findings presented in figure 1.

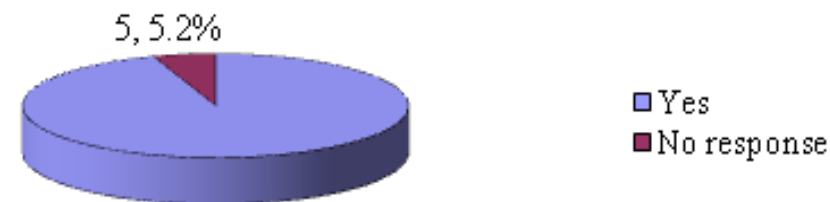

$91,94.8 \%$

Figure1. Distribution of Respondents on Teachers' Work and its Influence on other People's Lives

Findings in figure 1'indicate that $94.8 \%$ of the respondents agreed that their work has an influence on other people's lives. 44(45.8\%) indicated that their work as teachers influenced other people's lives to some extent whereas $46(49.0 \%)$ indicated that it was to a greater extent. However a minority of $5(5.2 \%)$ did not respond. All professions whether formal by going through formal education up to the highest level in formal learning institutions or informal learning through observation, imitating and intuition stem from a teacher. Therefore the contribution a secondary school teacher makes in one's life cannot go unnoticed.

On interviewing the school principals to comment on the psychological influence of burnout behaviour on productivity of teachers in schools bore the following results include; teachers who have served for long under Board of Management hoping to be employed. The long service, coupled with not being rewarded accordingly makes them lose interest in their work. The enthusiasm, vigor and energy to teach go down. They resort to use of drugs, drinking alcohol, smoking and absenteeism (Principal 001, 002, 004, 006, and 010). This is a clear indication of burnout behaviour which in effect affects the teachers' productivity.

The principals further indicated that; Parents use teachers as the scapegoat responsible at least in part for poor Kenya Certificate of Secondary (KCSE) results of students. Lack of appreciation from the parents for the efforts teachers put in to ensure that learning takes place and good results posted is frustrating. Teachers are lashed for poor student performance despite the fact that some students come in with very low marks and are not consistent in class attendance. 7(58.3\%) indicated that lack of appreciation from parents works negatively on teachers productivity since their efforts to perform is not realized (Principal 001, 004, 006, 008, 009, 010 and 012, 2017).

To confirm the psychological influence of burnout behaviour on the productivity of teachers, the researcher sought the opinion of the SDOE, (2017) who sat upright, and looking at me said, "Madam, teachers have no time for relaxation or recreation. They are too busy running up and down to ensure that they achieve their targets. This makes them fatigued and frustrated in effect lowering their productivity".

The findings support Smith, Sarason and Sarason (1982) who postulates that frustration in excellent performers causes emotional exhaustion, loss of enthusiasm and concern for their jobs; Shaufeli, 
Burnout Behaviour and its Psychological Influence on Productivity of Secondary School Teachers in Bungoma South Sub-County, Kenya

(2006) and López et.al (2008) indicated that discrepancy between professionals' efforts and the rewards the professionals receive in recognition and gratitude triggers burnout and Shaufeli, Leiter and Maslach (2008) stated that insufficient opportunities to rest and regenerate depleted energy aggravate the exhausting impact of demands/resource imbalances.

\section{Conclusions}

From the study findings presented, it was concluded that there is a moderate psychological influence of burnout behaviour on teachers' productivity. Based on the findings, the study recommends the following measures that would go a long way in curbing the psychological influence of burnout behavior on productivity of secondary school teachers hence enhanced teachers' productivity. To avoid fatigue due to overstaying of teachers in one school and in the same grade, the government should programme a suitable movement of teachers to different schools and grades after a given period. Secondly, parents must be obligated to play their role by paying the mandatory school fees on time so that students are not send away to collect fees. This will enable teachers to cover the syllabus in good time. Thirdly the school management should engage parents to appreciate the capabilities of their children so that they do not put unrealistic demands on the teachers. Some parents expect too high grades beyond the ability of their children.

\section{REFERENCES}

[1] Cohen, L., Manion, L., Morrison, K. \& Morrison, R.B. (2007) "Research methods in education" Routledge

[2] Kerlinger, F. N. \& Howard, B. L. (1999). Foundation of behavioral research (4 ${ }^{\text {th }}$ ed.). New York: HBJ College and School Division.

[3] Kombo, D. K. \& Tromp, D. L. (2006). Proposal and Thesis writing: An introduction. Nairobi: Pauline Publication.

[4] Kumar, R. (1999). Research Methodology A Step-by-step guide for beginners London: SAGE Publications Ltd.

[5] López, J. M.O., Santiago, J.M, AgustínGodás, Cristina Castro, Estíbaliz Villardefrancos\& Dolores Ponte, 2008.An integrative approach to burnout in secondary school teachers: Examining the Role of Student Disruptive Behaviour and Disciplinary Issues. International Journal of Psychology and Psychological Therapy.

[6] Maslach C, Schaufeli, W. B \&Leiter, M. P (2001). Job burnout. Annual Review Psychology. 52, 397-422.

[7] Maslach, C., Leiter, M.P. and Schaufeli, W.B. (2008), "Measuring burnout", in Cooper, C.L. and

[8] Cartwright, S. (Eds), The Oxford Handbook of Organizational Wellbeing, Oxford University Press, Oxford, pp. 86-108.

[9] Mugenda, O. M \&Mugenda, A.G. (2003). Research Methods: Quantitative and Qualitative Approaches. Nairobi: Acts Press.

[10] Ndugu, M.M. (2014), Quality and productivity of teachers in selected public secondary schools in Kenya. Medditerranean Journal of social sciences.

[11] Okumbe, J. A. (1999). Educational Management: Theory and Practice (2 ${ }^{\text {nd }}$ Ed.). Nairobi: Nairobi University Press, (Publishers).

[12] Orodho, J.A. (2005). Techniques of writing research proposals and reports in education and social sciences. Nairobi: Masola publishers

[13] OSO, W.Y.\& D. One, (2008): A general guide to writing Research Proposal and report. A Hand Book on beginning Researchers. $2^{\text {nd }}$ edition, Makerere University, Uganda.

[14] Sekaran, A. S. (2008) "Efficacy of credit risk management on the performance of banks in Nigeria: a Study of Union Bank Plc", Global Journal of Management and Business Research Administration and Management.

[15] Smith, E. R., Sarason, G. I., and Sarason, R. B. (1982). Psychology: The Frontiers of Behaviour Second Edition. Mexico: Haper \& Row, Publishers New York.

Citation: Catherine Meddiatrix Wanyonyi. "Burnout Behaviour and its Psychological Influence on Productivity of Secondary School Teachers in Bungoma South Sub-County, Kenya "International Journal of Managerial Studies and Research (IJMSR), vol 7, no. 5, 2019, pp. 1-6. doi: http://dx.doi.org/10.20431/23490349.0704001.

Copyright: () 2019 Authors. This is an open-access article distributed under the terms of the Creative Commons Attribution License, which permits unrestricted use, distribution, and reproduction in any medium, provided the original author and source are credited. 